\title{
Regional cerebral blood flow of patients with focal epilepsy studied using xenon enhanced CT brain scanning
}

\author{
D R FISH, T T LEWIS, D J BROOKS, E ZILKHA, R J S WISE, B E KENDALL \\ From the Institute of Neurology, Queen Square, London, UK
}

SUMMARY Stable xenon-enhanced X-ray computed tomography (XeCT) was used to measure the regional cerebral blood flow (rCBF) of 12 patients with drug resistant partial epilepsy and a marked unilateral focus on electroencephalography (EEG). Interictal mean rCBF of fixed regions of interest (ROIs) was reduced by $25 \%$ in the cortex of the epileptogenic cerebral lobe compared with the same regions on the contralateral side $(p<0.02)$. Six control scans showed a mean side to side cortical difference in $\mathrm{rCBF}$ of $14 \%$, whereas the epileptogenic focus was associated with a reduction in the cortical rCBF of greater than $30 \%$ in six out of the 12 patients. In an additional patient with partial epilepsy XeCT demonstrated significant focal hypoperfusion when interictal EEGs and conventional CT scans showed no abnormalities.

Stable xenon-enhanced X-ray computed tomography $(\mathrm{XeCT})$ has previously been used to measure regional cerebral blood flow (rCBF) in normal subjects, ${ }^{1}$ and patients with cerebrovascular disease. ${ }^{2}$ In a group of 19 resting normal subjects no significant differences between the rCBF of left and right cerebral structures were found. ${ }^{1}$ To date there have been no reported measurements using XeCT of rCBF in patients with focal epilepsy.

Regions of hypometabolism have been demonstrated interictally in approximately $50-70 \%$ of patients with focal epilepsy studied with positron emission tomography (PET) ${ }^{4-6}$ Such regions correspond most frequently to foci of mesial temporal sclerosis, although the areas of hypometabolism are generally found to be more extensive than the histological lesions. This is likely to be caused by the inactivation of associated structures. ${ }^{7}$

The presence of mesial temporal sclerosis is of clinical significance because these epileptic patients have a much better prognosis following surgery than patients without histological abnormalities. ${ }^{8}$ Consequently the detection of focal hypometabolism in patients with partial epilepsy may be of prognostic value. Metabolic studies using PET have demon-

Address for reprint requests: D R Fish, Institute of Neurology, Queen Square, London, WCIN 3BG, UK.

Received 1 February 1987 and in revised form 8 July 1987. Accepted 13 July 1987 strated focal abnormalities in patients with partial epilepsy that were not apparent from EEGs. ${ }^{9}$ PET, however, is not yet widely available and while single photon emission computed tomography (SPECT) may also be able to demonstrate changes in rCBF in patients with focal epilepsy, absolute flow values cannot readily be computed using this technique. ${ }^{10}$

At present the preoperative localisation of epileptic? foci is usually based on a combination of clinical features, routine and specialised EEGs, and radiology. Unfortunately good quality ictal EEG recordings cannot always be obtained. In this study we demonstrate the use of the potentially widely available $\mathrm{XeCT}$ technique as an adjunct to EEG in localising interictal regions of hypoperfusion in patients with focal epilepsy.

\section{Subjects}

The details of the 12 patients with focal epilepsy are listed in table 1 . The six control XeCT scans were obtained from five patients with generalised seizures who were not suitable for surgical treatment because of both the clinical and EEG findings. Four controls had generalised 3 per second spike and wave activity on ictal EEGs. The fifth control had bilateral abnormalities on psychometry, generalised spikes on his interictal EEG, and no focal discharges during sphenoidal ictal recordings. An additional patient was studied who had stereotyped partial seizures. Her interictal EEGs showed no abnormalities and ictal recordings could not be obtained because of relatively long periods between seizures. Three 
Table 1 Characteristics of patients with focal EEG abnormalities

\begin{tabular}{|c|c|c|c|c|c|c|}
\hline $\begin{array}{l}\text { Patient } \\
\text { number }\end{array}$ & $\begin{array}{l}\text { Age } \\
(y r)\end{array}$ & $\operatorname{Sex}$ & $\begin{array}{l}\text { Febrile } \\
\text { seizure }\end{array}$ & Features of seizure & EEG focus & Site of CT lesion \\
\hline 1 & 19 & $\mathrm{~F}$ & Yes & Left sided jerking & Right anterior temporal* & None \\
\hline 2 & 34 & $\mathrm{~F}$ & No & $\begin{array}{l}\text { Blank stare } \\
\text { Postictal dysphasia }\end{array}$ & Left anterior temporal ${ }^{*}$ & None \\
\hline 3 & 30 & $\mathrm{~F}$ & Yes & $\begin{array}{l}\text { Blank stare } \\
\text { Automatism }\end{array}$ & Deep right temporal* & None \\
\hline 4 & 28 & $\mathrm{~F}$ & No & $\begin{array}{l}\text { Right sided jerking } \\
\text { Automatism }\end{array}$ & Deep left temporal* & Left temporal \\
\hline 5 & 31 & $\mathbf{M}$ & No & $\begin{array}{l}\text { Automatism } \\
\text { Postictal dysphasia }\end{array}$ & Left anterior temporal ${ }^{*}$ & None \\
\hline 6 & 18 & $\mathbf{M}$ & Yes & $\begin{array}{l}\text { Blank stare } \\
\text { Automatism }\end{array}$ & Right anterior temporal & Dilated R temporal horn \\
\hline 7 & 34 & M & No & $\begin{array}{l}\text { Blank stare } \\
\text { Postictal dysphasia }\end{array}$ & Left anterior temporal & None \\
\hline 8 & 23 & $\mathrm{~F}$ & Yes & $\begin{array}{l}\text { Blank stare } \\
\text { Automatism }\end{array}$ & Right anterior temporal* & None \\
\hline 9 & 21 & $\mathrm{~F}$ & No & $\begin{array}{l}\text { Right sided jerking } \\
\text { Postictal dysphasia }\end{array}$ & Widespread left temporal & None \\
\hline 10 & 48 & $\mathbf{M}$ & No & $\begin{array}{l}\text { Confused thinking for a few seconds } \\
\text { Attacks cluster }\end{array}$ & Right frontal & Dilated posterior horns \\
\hline $\begin{array}{l}11 \\
12\end{array}$ & $\begin{array}{l}18 \\
30\end{array}$ & $\begin{array}{l}\mathrm{M} \\
\mathrm{M}\end{array}$ & $\begin{array}{l}\text { No } \\
\text { Yes }\end{array}$ & $\begin{array}{l}\text { Eyes turn to right } \\
\text { Brief kicking both legs }\end{array}$ & $\begin{array}{l}\text { Left frontal* } \\
\text { Left frontal }\end{array}$ & $\begin{array}{l}\text { Left frontal } \\
\text { Left frontal } \dagger\end{array}$ \\
\hline
\end{tabular}

*Denotes an ictal EEG recording.

+ Denotes MRI localisation.

further patient studies had to be excluded: one patient had an aura on commencing the test and the procedure was abandoned, and two patients moved during the procedure to such an extent that a reliable functional image could not be produced. All patients had had multiple EEGs, usually including sleep and prolonged telemetry. Sphenoidal electrodes and corticography were used when clinically indicated. Patient's seizure frequencies ranged from 1-100 per month. All subjects were clinically seizure free for at least 6 hours prior to the study.

\section{Methods}

This study had the approval of the Ethics Committee of The National Hospital for Nervous Diseases, and all patients gave their informed consent. rCBF was measured using XeCT scanning as described by Yonas et al. ${ }^{2}$ Scans were performed at $80 \mathrm{kV}, 200 \mathrm{mAS}$ with an IGE $9800 \mathrm{CT} / \mathrm{T}$ scanner using the commercially available CBF programme. Patients 1-12 were scanned in the plane containing the EEG focus. The slice position and angulation for temporal scans was determined so as to pass along the axis of the temporal lobe, avoiding the dense petrous bone and minimising artefactual streaking due to beam hardening. Typically the slices were angled $10-15^{\circ}$ caudal from the orbito-meatal line. In two patients a slice position $1 \mathrm{~cm}$ superior to the axis of the temporal lobe was used. In patient 2 this reduced bone streak artefact, and in Patient 4 this included the small area of low attenuation that had been shown on previous CT scans. Frontal scans were performed in the plane most appropriate to the focus, typically using reverse gantry tilt of $10^{\circ}$. Patient 5 had to be rescanned because his first study included little temporal lobe tissue.

Lateral and medial temporal regions of interest (ROI) of $7-10 \mathrm{~cm}^{2}$ were defined symetrically for the two hemispheres by one of us (TL) from the anatomical scan (see fig 1), with- out knowledge of the clinical, EEG or rCBF findings. Lateral regions of interest were defined as follows: $1 \mathrm{~cm}$ width strips were used starting $1 \mathrm{~cm}$ posterior to the anterior border of the temporal lobe. The strips extended posteriorly as far as the level of the trigone. The lateral border of each strip was subsequently positioned $3 \mathrm{~mm}$ medial to the lateral mar-

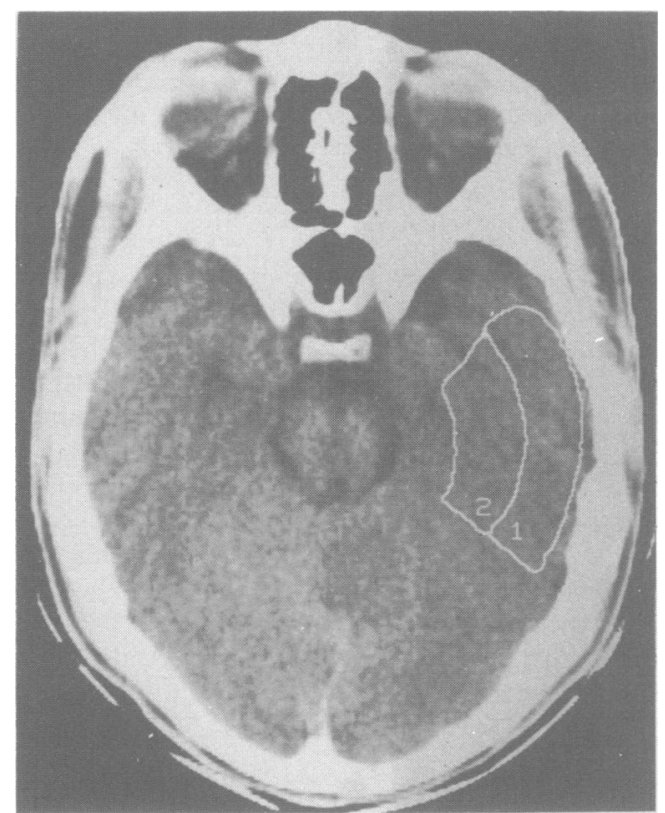

Fig 1. The left lateral and medial strips of Patient 6 on the anatomical scan. 
Table 2 The $\mathrm{rCBF}(\mathrm{ml} / \mathrm{min} / 100 \mathrm{~g}$ brain tissue) measured by $X e C T$ in planes that included the EEG focus

\begin{tabular}{|c|c|c|c|c|}
\hline \multirow[b]{2}{*}{$\begin{array}{l}\text { Patient } \\
\text { number }\end{array}$} & \multicolumn{2}{|l|}{ Lateral strip } & \multicolumn{2}{|l|}{ Medial strip } \\
\hline & $\begin{array}{l}\text { Unaffected } \\
\text { side }\end{array}$ & $\begin{array}{l}\text { Affected } \\
\text { side }\end{array}$ & $\begin{array}{l}\text { Unaffected } \\
\text { side }\end{array}$ & $\begin{array}{l}\text { Affected } \\
\text { side }\end{array}$ \\
\hline 1 & 83 & 48 & 50 & 46 \\
\hline 2 & 60 & 41 & 40 & 42 \\
\hline 3 & 37 & 35 & 43 & 29 \\
\hline 4 & 67 & 57 & 58 & 49 \\
\hline 5 & 69 & 43 & 37 & 27 \\
\hline 6 & 65 & 40 & 52 & 35 \\
\hline 7 & 34 & 38 & 22 & 9 \\
\hline 8 & 48 & $\begin{array}{l}30 \\
61\end{array}$ & 53 & 53 \\
\hline $\begin{array}{l}0 \\
9\end{array}$ & 70 & 58 & 30 & 38 \\
\hline 10 & 72 & 35 & 32 & 28 \\
\hline 11 & 79 & 54 & 73 & 69 \\
\hline 12 & 90 & 80 & 70 & 65 \\
\hline Mean & $65 t$ & 49 & $47^{*}$ & 41 \\
\hline
\end{tabular}

$\dagger p<0.02 ;{ }^{*} p<0.05$, Bonferroni statistics.

gin of the functional image. These dimensions were chosen to include as much of the temporal cortex as possible while minimising the inclusion of bone streak artefacts. Medial ROIs were placed contiguous to the lateral ROIs. They extended to the lateral border of the cavernous sinus. Frontal ROIs were similarly constructed as appropriate to the anatomical scan.

Both medial and lateral ROIs contained a mixture of grey and white matter. Approximately $50 \%$ of the lateral strips constituted peripheral cortical grey matter while the medial strips were a mixture of grey matter, white matter, and may on some occasions have included ventricle. It is likely that the medial strips contained less grey matter than the lateral strips. Once defined anatomically the ROIs were applied to the functional image and a printout of rCBF obtained. The hemisphere containing the EEG focus was designated the affected side, and the other hemisphere was designated the unaffected side. The percentage side to side difference was defined as: (higher side-lower side)/higher side $\times 100 \%{ }^{5}$

\section{Results}

The rCBF results are shown in tables 2 and 3. An example of $\mathrm{XeCT}$ is shown in fig 3. The patient group had a mean $25 \%$ reduction in the rCBF of the lateral strips on the affected side. The control group showed a mean $14 \%(S D=8 \%)$ side to side difference in rCBF between lateral strips. In six of the patients with partial epilepsy the rCBF of the lateral strip on the affected side was reduced by more than $30 \%$ (control mean +2 SD) compared with the normal side (fig 2). The percentage reduction in the $\mathrm{rCBF}$ of the medial strips on the affected side was only $13 \%$ in the patients with partial epilepsy. The control group showed a mean side to side difference in rCBF of $16 \%$ $(\mathrm{SD}=10 \%)$ for the medial strips.

\section{Case report}

Patient 18 was a 45 year old women with a 20 year history of attacks of altered consciousness. These usually started with
Table 3 Control rCBF values ( $\mathrm{ml} / \mathrm{min} / 100 \mathrm{~g}$ tissue)

\begin{tabular}{|c|c|c|c|c|c|}
\hline \multirow{2}{*}{$\begin{array}{l}\text { Patient } \\
\text { number }\end{array}$} & \multirow[b]{2}{*}{ Plane } & \multicolumn{2}{|c|}{ Lateral strip } & \multicolumn{2}{|c|}{ Medial strip } \\
\hline & & Right & Left & Right & Left \\
\hline $\begin{array}{l}13 \\
14 \\
15 \\
15 \\
16 \\
17 \\
\text { Mean }\end{array}$ & $\begin{array}{l}\text { Mid temporal } \\
\text { Mid temporal } \\
\text { Mid temporal } \\
\text { Inf. frontal } \\
\text { Mid temporal } \\
\text { Mid temporal }\end{array}$ & $\begin{array}{l}59 \\
34 \\
34 \\
37 \\
57 \\
42 \\
44\end{array}$ & $\begin{array}{l}71 \\
26 \\
30 \\
32 \\
69 \\
42 \\
45\end{array}$ & $\begin{array}{l}52 \\
14 \\
29 \\
24 \\
60 \\
23 \\
34\end{array}$ & $\begin{array}{l}63 \\
20 \\
24 \\
32 \\
61 \\
25 \\
38\end{array}$ \\
\hline
\end{tabular}

an aura of epigastric discomfort which spread up into the chest and neck, followed by a tingling sensation in the neck. A few seconds later she would turn her head to the left and then have a generalised convulsion. These attacks would last for about 5 minutes, and occurred approximately once a month in spite of anticonvulsant treatment. She had more frequent isolated epigastric auras that lasted for up to 3 minutes. There were no definite clinical, psychometric or CT lateralising features, and four interictal EEGs, including a sleep study, were within normal limits. XeCT scan in the midtemporal plane showed hypoperfusion of the right temporal lobe (fig 4) with right lateral and medial rCBF values of $40 \mathrm{ml} / \mathrm{min} / 100 \mathrm{~g}$ compared with left lateral and medial values of 63 and $53 \mathrm{ml} / \mathrm{min} / 100 \mathrm{~g}$ respectively.

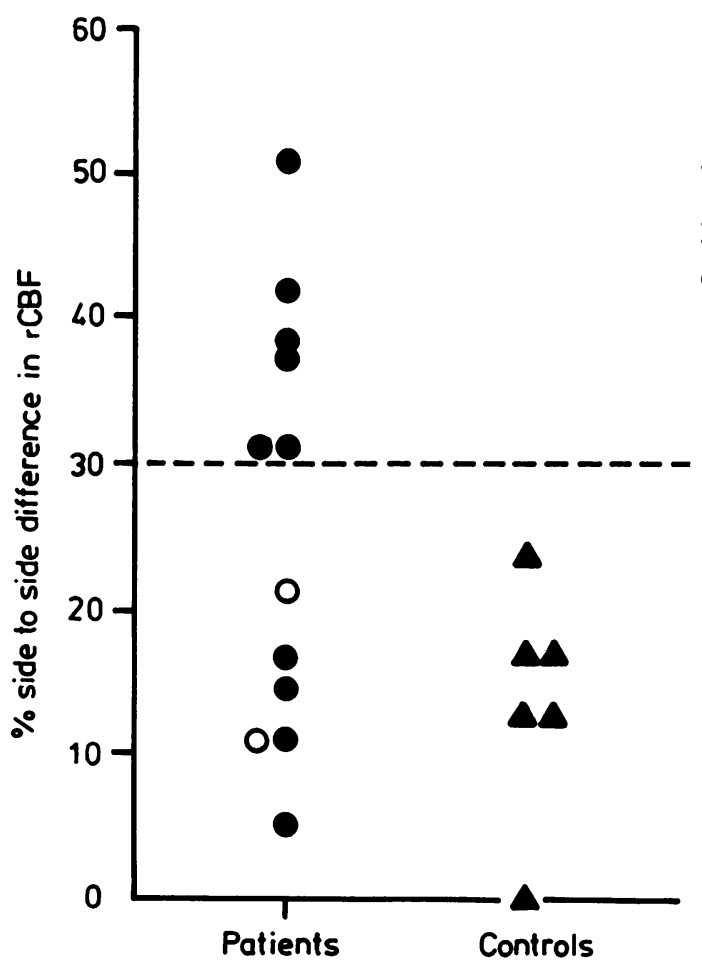

Fig 2 The percentage side to side differences in $\mathrm{CBF}$ of the lateral strips for patients and controls. Key: 1 Affected side $<$ unaffected side, $\bigcirc$ Affected side > unaffected side, Control subjects, --- mean $+2 S D$ of controls. 


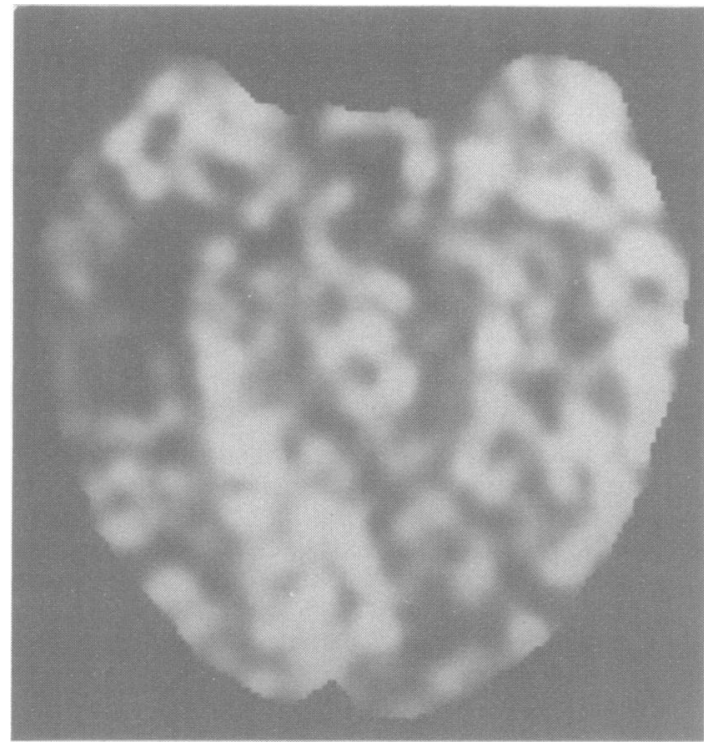

Fig 3 The XeCT of Patient 6.

\section{Discussion}

We have shown that XeCT can identify areas of hypoperfusion associated with epileptogenic foci. In six out of 12 patients with partial epilepsy the rCBF of affected cortex was reduced by more than $30 \%$ compared with the contralateral cortex. In a seventh patient with partial epilepsy, normal interictal EEGs, and normal temporal and frontal lobes on CT scanning, the XeCT technique identified a temporal focus of hypoperfusion, the rCBF being $37 \%$ lower on the affected side.

In agreement with previous workers ${ }^{2}$ we found that XeCT was tolerated reasonably well. During xenon inhalation five patients became lightheaded, and one felt as though she was looking down a yellow tunnel. These symptoms resolved immediately after xenon inhalation ceased. One patient had an absence seizure following $\mathrm{XeCT}$. It was noted that she was hyperventilating and this had often precipitated previous attacks.

Gur et al found that the main disadvantages of $\mathrm{XeCT}$ were low signal to noise ratio and artefacts produced by patient movement, ${ }^{11}$ and this was also our experience. The first would be improved by using higher concentrations of xenon but this could lead to anaesthesia. The second requires careful selection of patients who are highly motivated and compliant. Using the IGE CBF protocol our data suggest that a side to side difference of more than $30 \%$ in rCBF between lateral strips is clinically significant.

Functional imaging is unable to delineate the exact seat of EEG foci because regional hypofunction extends to associated structures. The lateral ROIs in the affected hemispheres of our patients with partial epilepsy demonstrated hypoperfusion more effectively than the medial ROIs. We suggest two possible explanations for this finding. Firstly, if an epileptic focus exerts maximal depression of function on cortex then it would be reasonable to expect the rCBF of the lateral ROIs to be more depressed than that of medial ROIs because lateral ROIs contain more grey matter. Secondly, in control subjects medial ROIs show a greater scatter in percentage side to side rCBF differences than lateral strips. This increased scatter in medial ROIs is probably a consequence of increased tissue heterogeneity and could obscure hypofunction. In practice we suggest that attention is focused on lateral rather than medial ROIs when rCBF side to side differences are being measured as part of the preoperative work up of patients with partial seizures.

Three patients have now been treated surgically. Patient 6, with a right temporal focus on his $\mathrm{XeCT}$, has been seizure free for 5 months following a right temporal lobectomy. Histology showed mild neuronal loss, and no vascular abnormality. Patient 11 , with a left frontal focus on $\mathrm{XeCT}$, was found to have a small supero-lateral frontal glioma and corticography revealed widespread left frontal discharges. Patient 12, with a normal XeCT, was found to have a small area of gliosis in the left medial frontal region, and corticography showed discharges confined to this region. Both patients 11 and 12 have been seizure free for the first postoperative month.

Our study suggests that XeCT may be a useful adjunct in the assessment of patients with intractable

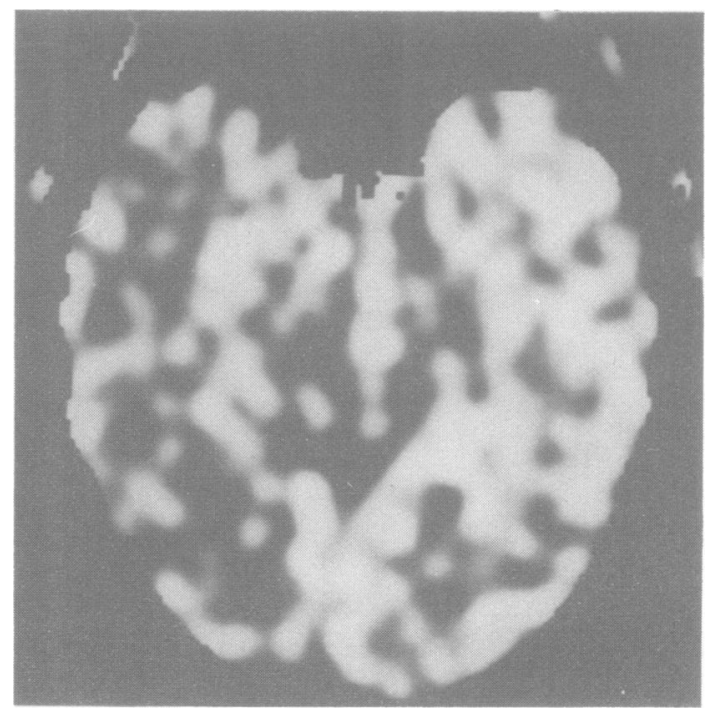

Fig 4 The XeCT of Patient 18. 
partial epilepsy. We are performing further studies on patients with focal and generalised epilepsy, and will correlate $\mathrm{XeCT}$ with surgical findings and outcome.

We thank the physicians of The National Hospital for Nervous Diseases for permission to study patients under their care, and the radiographers and Sister Redmond who helped to perform the scans.

\section{References}

1 Tachibana H, Meyer JS, Okayasu H, Kandula P. Changing patterns of cerebral blood flow with age measured by xenon CT. AJR 1984;1421027-34.

2 Yonas H, Wolfson SK, Gur D, et al. Clinical experience with the use of xenon-enhanced CT blood flow mapping in cerebral vascular disease. Stroke 1984;15:443-50.

3 Meyer JS, Hayman LA, Takahiro A, et al. Mapping local cerebral blood flow in humans during xenon inhalation. Stroke 1981;12:426-36.

4 Engel J, Kuhl DE, Phelps ME, Mazziotta JC. Interictal cerebral glucose metabolism in partial epilepsy and its relation to EEG changes. Ann Neurol 1982;12:510-7.
5 Theodore WH, Brooks R, Satos S, et al. The role of positron emission tomography in the evaluation of seizure disorders. Ann Neurol 1984;15S:S180-90.

6 Sperling MR, Wilson G, Engel J, Babb TL, Phelps M, Bradley $\mathbf{W}$. Magnetic reonance imaging in intractible partial epilepsy: correlative studies. Ann Neurol 1986;20:50-62.

7 Engel J, Brown WJ, Kuhl DE, Phelps ME, Mazziotta JC, Crandall PH. Pathological findings underlying focal temporal hypometabolism in partial epilepsy. Ann Neurol 1982;12:518-28.

8 Falconer MA, Serafetinides EA. A follow up study of surgery in temporal lobe epilepsy. $J$ Neurol Neurosurg Psychiatry 1963;26:154-65.

9 Engel J, Kuhl DE, Phelps ME, Crandall PH. Comparative localisation of epileptic foci in partial epilepsy by PCT and EEG. Ann Neurol 1982;12:529-37.

10 Lee BI, Markland ON, Siddiqui AR. Single photon emission computed tomography brain imaging using $\mathbf{N}, \mathbf{N}, \mathbf{N}^{\prime}-1,3$-propanediamine $2 \mathrm{HCl}$ (HIPDM): Intractable complex partial seizures. Neurology 1986;36:1471-7.

11 Gur D, Wolfson SK, Yonas H, et al. Progress in cerebral vascular disease: local cerebral blood flow by xenon enhanced CT. Stroke 1982;13:750-8. 